\title{
Laparo-endoscopic single site (LESS) versus multi- port operative laparoscopy for benign adnexal
}

\section{masses}

\begin{abstract}
Objective: The aim of the current study was to compare the use of the single port laparoscopy versus the use of the conventional multiport laparoscopy in the management of benign adnexal diseases.
\end{abstract}

Setting: Women's Health Hospital, Assiut University, Egypt.

Patients and methods: This was a non-randomized comparative study conducted between October 2014 and October 2016 in Women's Health Hospital at Assiut University, Egypt. The study included 60 cases: 40 of them by the conventional multiport laparoscopy, 20 of them by the single port laparoscopy with a confidence interval $95 \%$ and power $80 \%$.

Study outcomes included the mean duration of surgery, the amount of blood loss and need for blood transfusion, the mean total IM analgesia, the mean total numbers of doses of oral analgesics, the recovery duration, the mean time from surgery to unassisted ambulation, the mean post-operative hospital stay, the mean time to return to sexual activity and finally the overall satisfaction score from the procedure.

Results: The mean age of the participants in group I was $26.53 \pm 5.12$ years versus $24.75 \pm 3.78$ years in group II with no statistically significant difference between the two groups. The mean BMI in group I is $26.25 \pm 2.33$ versus $23.85 \pm 2.56$ in group II with a statistically higher difference $(\mathrm{p}=0.001)$. The mean duration of surgery in group I is $57.90 \pm 22.94$ minutes and in group II is $73.50 \pm 17.93$ with a statistically significant difference $(p=0.006)$. The mean dose of IM analgesic is $41.88 \pm 17.35 \mathrm{mg}$ in group I versus $76.25 \pm 27.48 \mathrm{mg}$ in group II with a statistically significant difference $(\mathrm{p}=0.000)$. The mean dose of oral analgesic is $416.25 \pm 84.84 \mathrm{mg}$ in group I versus $271.25 \pm 57.51 \mathrm{mg}$ in group II with a statistically significant difference $(\mathrm{p}=0.000)$. The mean recovery duration by minutes is $10.02 \pm 1.86$ in group I versus $9.70 \pm 1.26$ in group II with no statistically significant difference. The mean hospital stay by days is $1.78 \pm 0.66$ in group I versus $1.20 \pm 0.41$ in group II with a statistically significant difference (p-0.001). The mean time taken to early ambulation by hours is $7.58 \pm 1.89$ in group I versus $6.85 \pm 1.60$ in group II with no statistically significant difference.

Conclusion: LESS is better than conventional in post-operative pain in the first week, less in hospital stay length, less in time taken to sexual activity and better in the overall satisfaction score. However, LESS takes longer duration of surgery and more pain immediately after recovery in the first few hours post operatively.

Keywords: laparoscopy, adnexa masses, LESS, ovary
Volume 9 Issue 5 - 2018

\section{Mostafa M Kamel, Mohammed A Bedaiwy, Ahmed M Abbas, Safwat A Salman, Mohammed A Youssef}

Department of Obstetrics \& Gynecology, Faculty of Medicine, Assiut University, Egypt

Correspondence: Ahmed M Abbas MD, Department of Obstetrics \& Gynecology, Faculty of Medicine, Woman's Health Hospital, Assiut University, Assiut, Postal code 7I I I I, Egypt, Tel +201003385183,Emailbmr90@hotmail.com

Received: July 31, 2018 | Published: September 07, 2018

\section{Introduction}

Presence of adnexal mass is one of the most common indications for referral to the gynecologist. Adnexal masses can be discovered accidently in patients being evaluated for a gynecological complaint or even in asymptomatic patient. ${ }^{1}$

Laparoscopic surgery is a well-established alternative to open surgery across disciplines due to the benefits of laparoscopy on postoperative pain, cosmesis, hospital stay, and convalescence are widely recognized. ${ }^{2,3}$ Laparoscopy has wide applications in the field of reproductive surgery. Firstly, it has been used successfully for the assessment of different factors of infertility including the ovarian factor, the tubal factor and the unexplained infertility. Moreover, it has been used for pelvic reconstruction in patients with extensive adhesions and those with advanced endometriosis. ${ }^{4}$

The use of laparoscopy in the management of gynecologic malignancies has increased over the last 10 years. ${ }^{5}$ The safety of pelvic and para-aortic lymphadenectomy has been established by many surgeons. ${ }^{6}$ Patients with early carcinoma of the cervix are now undergoing hysterectomy after laparoscopic lymphadenectomy. ${ }^{7}$ Staging and second - Look procedures are now being performed laparoscopically in selected patients with carcinoma of the ovary. ${ }^{5,8}$

Laparo-Endoscopic Single Site Surgery (LESS) was first described in the gynecology literature in 1969; tubal ligation being the first procedure routinely performed through a single incision at the umbilicus. ${ }^{9}$ The first published report in general surgery appeared in 1992 with appendectomies. ${ }^{10}$ Currently, the debate continues of whether LESS has anything more to offer to the patient, to the surgeon, or to the health care industry compared with the conventional laparoscopic approach. ${ }^{11}$ Since that time, thousands of (LESS) procedures have been successfully performed in the united states, from general surgery to urologic, gynecologic and bariatric surgery applications.

When compared with traditional multi-port laparoscopic 
techniques, benefits of (LESS) techniques include less postoperative pain, less blood loss, faster recovery time, and better cosmetic results "Despite the potential advantages of LESS techniques, there may be complication. ${ }^{12,13}$ Potential complications include significant post operative pain injury to organs, bleeding, infection, incisional hernia, intestinal adhesions and scarring. ${ }^{14,15}$

A 2016 review found no difference in complication rates comparing LESS hysterectomy to conventional hysterectomy for both major and minor complications. ${ }^{16}$ Single incision laparoscopic surgery is a very exciting new modality in the field of minimal access surgery which works for further reducing the scars of standard laparoscopy towards scarless surgery ${ }^{17}$

In our study, we compared the use of the single port laparoscopy versus the use of the conventional multiport laparoscopy in the management of benign adnexal diseases.

\section{Methods}

This was a non-randomized comparative study conducted between October 2014 and October 2016 in Women's Health Hospital at Assiut University, Egypt. All patients signed an informed consent form submitted for approval from Assiut Medical School Ethical Review Board.

The patients were recruited from those visited the outpatient gynecological clinic and those admitted inpatient units in Women's Health Hospital. Patients diagnosed with a variety of benign adnexal lesions who are candidates for surgical interventions were included in the study. We excluded those with pelvic infection, suspected malignancy, prior laparotomy including CS, morbid obesity (BMI $>30$ ), medical co-morbidities as DM, hypertension and finally those with large adnexal masses more than $6 \mathrm{~cm}$ in diameter.

The study included 60 cases: 40 of them by the conventional multiport laparoscopy, 20 of them by the single port laparoscopy with a confidence interval $95 \%$ and power $80 \%$.

All patients, after signing the consent, were subjected to the following: Full history taking, general examination, local vaginal examination and bimanual examination, weight and height measurements for calculation of the body mass index(BMI). Ultrasound evaluation was done using a SonoAce X8 machine (Medison, Korea) with multifrequency transabdominal and transvaginal probes.

In LESS cases, all surgical steps were performed through the transumbilical single port without insertion of addition ports or any extraumbilical instruments. ${ }^{4}$ Under general anesthesia and endotracheal intubation, the patient was placed in the low lithotomy position. Access was gained using a modified open Hasson technique, with a $1,8-\mathrm{cm}$ horizontal umbilical incision. ${ }^{18}$ The rectus fascia was sharply incised, and a Covidien single access (Coviedien, Mansfield MA, USA) multichannel part was inserted in the peritoneal cavity. The port has an insufflation channel that allows carbon dioxide insufflation with the pressure set at $15 \mathrm{~mm} \mathrm{Hg}$. The conventional 30 degree laparoscope was used. If the flexible scope is to be used, the tip of the scope can be adjusted to the center of the surgical field without moving the straight segment to provide adequate triangulation and avoid clashing with the surgeon's instruments. ${ }^{19}$

Left pelvic side wall adhesions were be released from the lateral pelvic wall using flexible or conventional laparoscopic shears (Cambridge Endo, Framingham, MA), which help to improve the surgical range of motion to reach extreme angles in the pelvis. ${ }^{20}$ We then grasped the tubes and ovaries, brought them through the multichannel port after detaching all the trocars from the abdomen. Curved instruments (Pnavel Systems, Morganville, NJ) and articulating graspers (Novare Surgical Systems, Cupertion, CA). Was helpful in providing efficient retraction to optimize surgical exposure. Deep infiltrating endometriotic implants was carefully dissected of the surrounding structures and excised. In a similar fashion, endometriosis of the surface of the urinary bladder was also removed. ${ }^{21}$

In multiport cases, Patient kept in steep trendelenburg and lithotomy position. One assistant stand between the legs of the patient to do uterine manipulation whenever required. Position should be in accordance with baseball diamond concept. Properly placed uterine manipulator is important to get a good exposure of ovary and tube. It is sometimes difficult to mobilize the uterus and the uterine ovarian ligament can be grasped by one of the traumatic grasper to lift and isolate the ovary or the ovary can be wedged against the pelvic sidewall using the flattened edges of the opened or closed forceps. ${ }^{4}$ It is important to remember that overly aggressive manipulation can cause lacerations in the capsule, follicles, or cysts and result in bleeding. Before starting the procedure, we observed the course of the ureter as it crosses the external iliac artery near the bifurcation of the common iliac artery at the pelvic brim. The left ureter can be more difficult to find because it is often covered by the base of the sigmoid mesocolon. ${ }^{19}$

Many time anatomic landmarks are distorted by adhesions endometriosis, or prior surgical exploration. In those cases dissection started from the most normal area and then it should proceed toward the more distorted parts of the operative field. At the end of the procedure, the operative field was inspected and any clots were removed with a suction-irrigator or grasping forceps. Pedicles are inspected under water and with decreased pneumoperitoneum and any bleeding if present can be controlled with bipolar electrocoagulation. ${ }^{20,21}$

All patients were reevaluated after two weeks. Patients were asked about the time taken for them to resume full domestic function and sexual activity. They were also interviewed regarding their level of satisfaction with the appearance of the surgical scar and their overall level of satisfaction with the procedure. Overall patient satisfaction with the procedure was scored on a numerical 1 to 10 scale, with 1 representing lowest level of satisfaction and 10 representing highest level of satisfaction. ${ }^{22}$

Study outcomes included the mean duration of surgery, the amount of blood loss and need for blood transfusion, the mean total IM analgesia (Pethidine dose), the mean total numbers of doses of oral analgesics, the recovery duration, the mean time from surgery to unassisted ambulation, the mean post-operative hospital stay, the mean time to return to sexual activity and finally the overall satisfaction score from the procedure.

\section{Statistical analysis}

Data were processed using Statistical Package of Social Sciences version 22.0 (SPSS version 22.0 Inc., Chicago, IL, USA). Quantitative data were expressed as means \pm standard deviation (SD) as appropriate. Qualitative data was expressed as frequency (numbers) and percentages. Fisher exact test and T. test were used to compare qualitative variables and Mann-Whitney test was used to compare quantitative variables between groups. A probability value ( $\mathrm{p}$-value $)<$ 0.05 was considered statistically significant. 


\section{Results}

Sixty cases were recruited in our study, 40 cases done by the conventional multiport laparoscopy (group I) and 20 cases done by the single port laparoscopy (group II). The mean age of the participants in group I was $26.53 \pm 5.12$ years versus $24.75 \pm 3.78$ years in group II with no statistically significant difference between the two groups. The percentage of rural residency is $(60 \%)$ in group I versus $(65 \%)$ in group II while the percentage of urban residency $(40 \%)$ in group I versus (35\%) in group II with no statistically significant difference. The mean BMI in group I is $26.25 \pm 2.33$ versus $23.85 \pm 2.56$ in group II with a statistically higher difference $(\mathrm{p}=0.001)$ (Table 1$)$

Table I Demographic data of the study participants

\begin{tabular}{|c|c|c|c|}
\hline & Group I $(n=40)$ & Group II $(n=20)$ & P-value \\
\hline \multicolumn{4}{|l|}{ Age: (years) } \\
\hline Mean \pm SD & $26.53 \pm 5.12$ & $24.75 \pm 3.78$ & 0.299 \\
\hline Range & $19.0-40.0$ & $19.0-31.0$ & \\
\hline \multicolumn{4}{|c|}{ Residency: No. (\%) } \\
\hline Rural & 24 (60.0\%) & I 3 (65.0\%) & 0.707 \\
\hline Urban & $16(40.0 \%)$ & 7 (35.0\%) & \\
\hline \multicolumn{4}{|l|}{ BMI $\left(\mathrm{kg} / \mathrm{m}^{2}\right):$} \\
\hline Mean \pm SD & $26.25 \pm 2.33$ & $23.85 \pm 2.56$ & $0.001 *$ \\
\hline Range & $20.0-29.0$ & $19.0-29.0$ & \\
\hline $\begin{array}{l}\text { Passive smoking: } \\
\text { No. (\%) }\end{array}$ & $23(57.5 \%)$ & II (55.0\%) & 0.854 \\
\hline
\end{tabular}

*Statistical significant difference

BMI, body mass index; SD, standard deviation; Group I, conventional laparoscopy group; Group II, single port group

Table 2 shows that there is no statistically significant difference between the indications of laparoscopy in both groups. Table 3 shows the mean duration of surgery in group I is $57.90 \pm 22.94$ minutes and in group II is $73.50 \pm 17.93$ with a statistically significant difference $(\mathrm{p}=0.006)$. There is no statistically significant difference between group I and group II as the mean amount of blood loss is $84.00 \pm 75.85 \mathrm{cc}$ in group I versus $45.00 \pm 12.14 \mathrm{cc}$ in group II. Similarly, no statistically significant difference according the need of blood transfusion between both groups ( $\mathrm{p}=0.291$ ).

Table 2 The indications of laparoscopy in the study participants

\begin{tabular}{llll}
\hline Diagnosis & $\begin{array}{l}\text { Group I } \\
(\mathbf{n}=\mathbf{4 0})\end{array}$ & $\begin{array}{l}\text { Group II } \\
(\mathbf{n}=\mathbf{2 0})\end{array}$ & P-value \\
\hline Dermoid cyst & $3(7.5 \%)$ & $\mathrm{I}(5.0 \%)$ & $\mathrm{I}$ \\
Ectopic pregnancy & $6(15.0 \%)$ & $\mathrm{I}(5.0 \%)$ & 0.407 \\
Endometriotic cyst & $5(12.5 \%)$ & $\mathrm{I}(5.0 \%)$ & 0.653 \\
Hemorrhagic cyst & $2(5.0 \%)$ & $2(10.0 \%)$ & 0.595 \\
Simple ovarian cyst & $9(22.5 \%)$ & $5(25.0 \%)$ & $\mathrm{I}$ \\
PCO & I5 (37.5\%) & I0 (50.0\%) & 0.355 \\
\hline
\end{tabular}

PCO, polycystic ovaries; Group I, conventional laparoscopy group; Group II, single port group

The mean dose of IM analgesic is $41.88 \pm 17.35 \mathrm{mg}$ in group I versus $76.25 \pm 27.48 \mathrm{mg}$ in group II with a statistically significant difference $(p=0.000)$. The total dose of oral analgesia which was calculated by multiplying the dose by the number of doses by the number of days. The mean dose of oral analgesic is $416.25 \pm 84.84 \mathrm{mg}$ in group I versus $271.25 \pm 57.51 \mathrm{mg}$ in group II with a statistically significant difference $(\mathrm{p}=0.000)$.

In Table 4 , the postoperative data was presented. The mean recovery duration by minutes is $10.02 \pm 1.86$ in group I versus $9.70 \pm 1.26$ in group II with no statistically significant difference. The mean hospital stay by days is $1.78 \pm 0.66$ in group I versus $1.20 \pm 0.41$ in group II with a statistically significant difference $(\mathrm{p}-0.001)$. The mean time taken to early ambulation by hours is $7.58 \pm 1.89$ in group I versus $6.85 \pm 1.60$ in group II with no statistically significant difference. The mean time taken to normal sexual activity by days is $15.58 \pm 7.18$ in group I versus $9.95 \pm 6.75$ in group II with a statistically significant difference $(\mathrm{p}=0.005)$. The mean of the overall satisfaction score is $5.23 \pm 1.48$ in group I of patients versus $7.10 \pm 1.12$ in group II of patients and the range of the score is from 2.0-8.0 in group I of patients versus 5.09.0 in group II of patients with a statistically significant difference between the two groups $(\mathrm{p}=0.000)$.

Table 3 Intra-operative data of the study groups

\begin{tabular}{|c|c|c|c|}
\hline & Group I $(n=40)$ & Group II $(n=20)$ & P-value \\
\hline \multicolumn{4}{|c|}{ Duration of surgery: (min) } \\
\hline Mean \pm SD & $57.90 \pm 22.94$ & $73.50 \pm 17.93$ & $0.006 *$ \\
\hline Range & $30.0-105.0$ & $50.0-100.0$ & \\
\hline \multicolumn{4}{|c|}{ Amount of blood loss: (cc) } \\
\hline Mean \pm SD & $84.00 \pm 75.85$ & $45.00 \pm 12.14$ & 0.199 \\
\hline Range & $20.0-350.0$ & $30.0-80.0$ & \\
\hline \multicolumn{4}{|c|}{ Blood transfusion: No. (\%) } \\
\hline Yes & $4(10.0 \%)$ & $0(0.0 \%)$ & 0.291 \\
\hline No & $36(90.0 \%)$ & $20(100.0 \%)$ & \\
\hline
\end{tabular}

SD, standard deviation; Group I, conventional laparoscopy group; Group II, single port group

Table 4 Post-operative data of the study groups

\begin{tabular}{|c|c|c|c|}
\hline & Group I $(n=40)$ & Group II $(n=20)$ & P-value \\
\hline \multicolumn{4}{|c|}{ Recovery duration: (min) } \\
\hline Mean \pm SD & $10.02 \pm 1.86$ & $9.70 \pm 1.26$ & 0.578 \\
\hline Range & $6.0-15.0$ & $8.0-12.0$ & \\
\hline \multicolumn{4}{|c|}{ Hospital stay: (days) } \\
\hline Mean \pm SD & $1.78 \pm 0.66$ & $\mathrm{I} .20 \pm 0.4 \mathrm{I}$ & $0.001 *$ \\
\hline Range & $1.0-3.0$ & $1.0-2.0$ & \\
\hline \multicolumn{4}{|c|}{ Time taken to early ambulation: (hours) } \\
\hline Mean \pm SD & $7.58 \pm 1.89$ & $6.85 \pm 1.60$ & 0.149 \\
\hline Range & $4.0-12.0$ & $4.0-10.0$ & \\
\hline \multicolumn{4}{|c|}{ Time taken to sexual activity: (days) } \\
\hline Mean \pm SD & $15.58 \pm 7.18$ & $9.95 \pm 6.75$ & $0.005^{*}$ \\
\hline Range & $7.0-28.0$ & $1.0-28.0$ & \\
\hline
\end{tabular}

*Statistical significant difference

SD, standard deviation; Group I, conventional laparoscopy group; Group II, single port group 


\section{Discussion}

About $10 \%$ of women undergo exploratory surgery for evaluation of adnexal masses during their life time. The aim of the current study over a period of two years was to compare (LESS) to the conventional laparoscopy in management of adnexal masses. There is only statistically significant difference between the two groups regarding BMI explained as it is a new surgical technique, we selected less BMI for fear of failure, transport to conventional technique or open surgery, intraoperative or postoperative complications related to the increased BMI and more prolongation to the operative time. Difficulty in closure of the port site in obese patients and the possibility of part site hernia post-operative is more suspected with the obese patients. The distance between the umbilicus and the target organ changes in obese patients, for these reasons obese patients may not be good candidates for LESS. $^{20}$

In our study, there is increase in the duration of surgery with the LESS group, this is agreeing with what we mentioned in the review of literature as with the learning curve with any new surgical techniques, it will take a long time in the beginning but by performing more cases, the operation time begins to decrease until it reaches a plateau. ${ }^{7}$

Also, as with most new surgical techniques, the early development of LESS surgery was fraught with problems, the main problems with performing LESS surgery are: loss of triangulation, clashing of instruments, telescope and comer ahead and lack of maneuverability. Those factors are sharing in the causes of the more prolonged operative time in the (LESS) group. ${ }^{23}$

The use of analgesia either immediately after recovery or during the next post operative week is different between the two groups with a statistically significant difference. Immediately after recovery, we used more concentrations (doses) of analgesia in the group II done by LESS, while we used more doses of analgesia in the group I done by the conventional multiport laparoscopy in the next post operative week. These results are not coinciding with Meta-analysis study on pooled data as revealed no significant difference between LESS and conventional laparoscopy. ${ }^{24}$

This is explained by: The increased pain in our study in the first few hours immediately after recovery in the group II may be due to: Larger port system in the single port, Decreased the angle of freedom, Incisions in the umbilicus cause pain with respiratory movement, Prolonged operative time and more manipulations causing visceral pain as it is a new surgical technique and it will have its normal learning curve onwards.

The use of more analgesia in the first few days after surgery is more with the conventional laparoscopy. These results agree with what mentioned in the literature, this is due to: decreased number of ports which is associated with fewer painful points after surgery, Subsequent fewer potential locations for wound complications including bleeding and infection.

There is a difference between group I and group II according to hospital stay, with a statistically significant difference showing that the (LESS) is associated with shorter hospital stay than the conventional laparoscopy. These results coincide with what mentioned in the review of literature. ${ }^{7,25}$ These authors declared that faster recovery following LESS leads to a reduced time of returning to work and in turn shorter time to regain normal sexual activity.
There is no statistically significant difference between group I and group II according to the time taken to early ambulation by hours while the time taken to normal sexual activity (few days) is less with group II which was done by the single port laparoscopy.

Our results showing also no difference between group I and group II according to scar satisfaction, these results coincide with what mentioned in the literature. Reduced number of ports causes fewer scars. Although LESS port needs a $2 \mathrm{~cm}$ incision, it is usually concealed in the umbilicus. Therefore, in some cases the minimally invasive surgery may even by virtually scar less. ${ }^{26}$ However, other studies investigated the cosmetic outcomes have not reported a significant difference between LESS and CLS in abdominal procedures. ${ }^{7,25}$

In our study, there is a statistically significant difference between group I and group II, showing that there is more overall satisfaction score in group II than that in group I. these results coincide and agree with what reported in the review of literature. However, standardized methods of measuring patient's satisfaction should be used in large sample size randomized controlled trials (RCTs) to compare satisfaction between single port laparoscopy groups and conventional laparoscopy groups.

\section{Conclusion}

The present study demonstrated that the LESS approach is a promising method of laparoscopy and we compared between it and the conventional multiport operative laparoscopy. LESS is better than conventional in post-operative pain in the first week, less in hospital stay length, less in time taken to sexual activity and better in the overall satisfaction score. However, LESS takes longer duration of surgery and more pain immediately after recovery in the first few hours post operatively.

The present study represents a small size population, which was one of our limitations, so large population size studies are recommended, with more inclusion criteria to reach more informative results and put clear values for different variables and more diagnostic models than that used in this study. Our recommendations, regarding LESS are more training, more cases to increase the learning curve especially the residents in the tertiary hospitals to overcome the increased operative time and in turn the pain immediately after recovery. Uniforming one diagnosis will help more training, more experience and judgment in LESS surgery, as ectopic pregnancy either undisturbed, disturbed and chronic ectopic pregnancy. Encouraging all highly experience surgeons in the conventional laparoscopy to use the LESS and train the residents as LESS is considered a growing minimally invasive future laparoscopic surgery.

\section{Acknowledgments}

None.

\section{Conflicts of interest}

The author declares that they have no conflict of interest.

\section{References}

1. Gaughan E, Javaid T, Cooley S. Study of ovarian cancer management. Irish medical journal. 2006;99(9):279-280.

2. Ali MK, Abdelbadee AY, Abbas AM, et al. Laparoendoscopic singlesite surgery in gynaecologic oncology. World J Laparosc Surg. 2012;5(3):121-127. 
3. Boruta DM. Laparoendoscopic single-site surgery in gynecologic oncology: an update. Gynecol Oncol. 2016;141(3):616-623

4. Ahmed K, Wang TT, Patel VM, et al. The role of single-incision laparoscopic surgery in abdominal and pelvic surgery: a systematic review. Surg Endosc. 2011;25(2):378-396.

5. Zullo F, Falbo A, Palomba S. Safety of laparoscopy vs laparotomy in the surgical staging of endometrial cancer: a systematic review and metaanalysis of randomized controlled trials. Am J Obstet Gynecol. 2012;207(2):94-100

6. Azziz M, Frumovitz M, Greer M, et al. Trends in laparoscopic and robotic surgery among gynecologic oncologists: a survey update. Gynecol Oncol. 2004;112(3):501-505

7. Fader AN, Escobar PF. Laparoendoscopic single-site surgery (LESS) in gynecologic oncology: Technique and initial report. Gynecol Oncol. 2009; 114:157-161.

8. Ali MK, Abdelbadee AY, Shazly SA, et al. Robotic gynecological surgery: a clinical approach. World J Laparoscop Surg. 2013;6(3):156-162.

9. Scott F, Cromi A, Fasola M, et al. One trocar salpingectomy for the treatment of tubal pregnancy: a 'marionette-like'technique. BJOG. 2007;112(10):1417-1419.

10. Koh AR, Lee JH, Choi JS, et al. Singleport laparoscopic appendectomy during pregnancy. Surg Laparosc Endosc Percutan Tech. 2012;22(2):e83e86.

11. Kommu SS, Kaouk JH, Rané A. Laparo-endoscopic single-site surgery: preliminary advances in renal surgery. BJU international. 2009;103(8):1034-1037.

12. Hall TC, Dennison AR, Bilku DK, et al. Single-incision laparoscopic cholecystectomy: a systematic review. Arch Surg. 2012;147(7):657-666.

13. Aarts JW, Nieboer TE, Johnson N, et al. Surgical approach to hysterectomy for benign gynaecological disease. The Cochrane Library. 2015;(8):Cd003677.

14. Song T, Kim ML, Jung YW, et al. Laparoendoscopic single-site versus conventional laparoscopic gynecologic surgery: a metaanalysis of randomized controlled trials. Am J Obstet Gynecol. 2013;209(4):317.

15. Mittermair C, Schirnhofer J, Brunner E, et al. Single port laparoscopy in gastroenterology and hepatology: a fine step forward. World $J$ Gastroenterol. 2014;20(42):15599-15607.
16. Sandberg EM, la Chapelle CF, van den Tweel MM, et al Laparoendoscopic single-site surgery versus conventional laparoscopy for hysterectomy: a systematic review and meta-analysis. Arch Gynecol Obstet. 2017;295(5):1089-1103.

17. Sajid MS, Ladwa N, Kalra L, et al. Single-incision laparoscopic cholecystectomy versus conventional laparoscopic cholecystectomy: metaanalysis and systematic review of randomized controlled trials. World J Surg. 2012;36(11):2644-2653.

18. Escobar PF, Bedaiwy MA, Fader AN, et al. Laparoendoscopic singlesite (LESS) surgery in patients with benign adnexal disease. Fertil Steril. 2010;93(6):2074

19. Pontis A, Sedda F, Mereu L, et al. Review and meta-analysis of prospective randomized controlled trials (RCTs) comparing laparo-endoscopic single site and multiport laparoscopy in gynecologic operative procedures. Arch Gynecol Obstet. 2016;294(3):567-577.

20. Murji A, Patel VI, Leyland N, et al. Single-incision laparoscopy in gynecologic surgery: a systematic review and meta-analysis. Obstet Gynecol. 2013;121(4):819-828.

21. Malik M, McCormack K, Krukowski ZH, et al. Single port/incision laparoscopic surgery compared with standard three-port laparoscopic surgery for appendicectomy-a randomised controlled trial. Trials. 2012;13(1):201.

22. Abdellah MS, Abbas AM, Hegazy AM, et al. Vaginal misoprostol prior to intrauterine device insertion in women delivered only by elective cesarean section: a randomized double-blind clinical trial. Contraception. 2017;95(6):538-543.

23. Tacchino RM, Greco F, Matera D, et al. Single incision laparoscopic gastric bypass for morbid obesity. Obes Surg. 2010;20(8):1154-1160.

24. Garg P, Thakur JD, Garg M, et al. Single-incision laparoscopic cholecystectomy vs. conventional laparoscopic cholecystectomy: a meta-analysis of randomized controlled trials. J Gastrointest Surg. 2012;16(8):1618-1628.

25. Podolsky ER, Rottman SJ, Curcillo PG. Single port access (SPA) cholecystectomy: Two year follow-up. JSLS. 2009;13(4):528-535.

26. Leroy J, Cahill RA, Asakuma M, et al. Single-access laparoscopic sigmoidectomy as definitive surgical management of prior diverticulitis in a human patient. Arch Surg. 2009;144:173-179. 